\title{
Intra-abdominal fat accumulation is an important predictor of metabolic syndrome in young adults
}

\author{
Masakazu Kobayashi, MDa,* (D), Sayaka Ogawa, PhDa, Jun Tayama, PhDº, Ikuko Sagara, MDa \\ Atsushi Takeoka, MDa , Peter Bernick, MSW' ${ }^{c}$, Tetsuya Kawano, MD ${ }^{a}$, Norio Abiru, MD ${ }^{d}$, \\ Masaki Hayashida, MD ${ }^{\mathrm{a}, \mathrm{e}}$, Susumu Shirabe, $\mathrm{MD}^{\mathrm{a}, \mathrm{f}}$
}

\begin{abstract}
Metabolic syndrome (MetS), mainly caused by intra-abdominal fat (IAF) accumulation, is an important risk factor for cardiovascular disease. The prevalence of MetS increases rapidly after the age of 40 years, and it is presumed that there is a substantial proportion of MetS in younger age groups. However, the association of IAF with MetS in adults aged 20 to 30 years has not been fully investigated.

This study aimed to determine the prevalence of MetS and to verify whether IAF accumulation is associated with other MetSrelated metabolic disorders including dyslipidemia, high blood pressure, and high blood glucose among the Japanese population in their 20s.

In this cross-sectional study, IAF area (IAFA) and MetS-related metabolic parameters were evaluated in university students in their 20s ( $n=1822,21.5 \pm 1.5$ years). IAFA was measured using a non-invasive device, DUALSCAN, which can be readily measured through the dual impedance method. The participants were divided into four groups according to IAFA: 0-49.9, 50-74.9, 75-99.9, and $\geq 100 \mathrm{~cm}^{2}$.

MetS was prevalent in $3.3 \%$ and $0.0 \%$ of the males and females, respectively, according to the Japanese criteria of MetS. The sexand lifestyle-adjusted odds ratios (ORs) for the three metabolic component levels of Mets were elevated in the larger IAFA groups compared to the smallest IAFA group, according to the level of IAFA. The levels particularly increased in participants with abdominal obesity, defined by both, IAFA and waist circumference rather than by waist circumference alone.

IAF accumulation was significantly associated with MetS-related metabolic disorders in young adults. An evaluation of IAFA may contribute to the early prediction of the risk of developing MetS in the future.

Abbreviations: $95 \% \mathrm{Cl}=95 \%$ confidence intervals, $\mathrm{BIA}=$ bioelectrical impedance analysis, $\mathrm{BP}=$ blood pressure, $\mathrm{DBP}=$ diastolic blood pressure, FPG = fasting plasma glucose, HDL-C = high density lipoprotein-cholesterol, IAF = intra-abdominal fat, IAFA = intra-abdominal fat area, MetS = Metabolic syndrome, $\mathrm{OR}=$ odds ratio, $\mathrm{SBP}=$ systolic blood pressure, $\mathrm{TG}=$ triglycerides, $\mathrm{WC}=$ waist circumference.
\end{abstract}

Keywords: bio-impedance, intra-abdominal fat, metabolic syndrome, visceral, young

\section{Introduction}

Metabolic syndrome (MetS), mainly caused by intra-abdominal fat (IAF) accumulation, is an important risk factor of cardiovascular disease; the incidence is increasing annually. ${ }^{[1-3]}$ In Japan, the clinical criteria for MetS required the presence of
IAF accumulation (waist circumference [WC] of $\geq 85 \mathrm{~cm}$ and $\geq$ $90 \mathrm{~cm}$ for males and females, respectively, which corresponds to IAF accumulation of $\geq 100 \mathrm{~cm}^{2}$ ), and any 2 of the following three mild metabolic disorders:

(1) dyslipidemia,

Editor: Fabio Comim.

This study was supported by grants from the Japan Society for the Promotion of Science (JSPS) for the Grant-in-Aid for Scientific Research (C) (No. 26350835). The funders had no role in study design, data collection and analysis, decision to publish, or preparation of the manuscript.

The authors of this work have nothing to disclose.

The data that support the findings of this study are available from a third party, but restrictions apply to the availability of these data, which were used under license for the current study, and so are not publicly available. Data are available from the authors upon reasonable request and with permission of the third party.

${ }^{a}$ Center for Health and Community Medicine, Nagasaki University, Nagasaki, ${ }^{b}$ Faculty of Human Science, Waseda University, Saitama, ${ }^{c}$ Student Accessibility Office, Nagasaki University, ${ }^{d}$ Department of Endocrinology and Metabolism, Nagasaki University Graduate School of Biomedical Sciences, ${ }^{\circledR}$ Akiyama Hospital, Nagasaki Japan, ${ }^{f}$ Research Center for the Control and Prevention of Infectious Diseases, Nagasaki University, Nagasaki, Japan.

* Correspondence: Masakazu Kobayashi, Center for Health and Community Medicine, Nagasaki University, Nagasaki Prefecture, Nagasaki, Bunkyomachi, 1-14, Japan (e-mail: masakazu-f328@nagasaki-u.ac.jp).

Copyright (C) 2020 the Author(s). Published by Wolters Kluwer Health, Inc.

This is an open access article distributed under the Creative Commons Attribution License 4.0 (CCBY), which permits unrestricted use, distribution, and reproduction in any medium, provided the original work is properly cited.

How to cite this article: Kobayashi M, Ogawa S, Tayama J, Sagara I, Takeoka A, Bernick P, Kawano T, Abiru N, Hayashida M, Shirabe S. Intra-abdominal fat accumulation is an important predictor of metabolic syndrome in young adults. Medicine 2020;99:37(e22202).

Received: 25 February 2020 / Received in final form: 15 July 2020 / Accepted: 15 August 2020

http://dx.doi.org/10.1097/MD.0000000000022202 
(2) increased blood pressure (BP), and

(3) elevated fasting plasma glucose (FPG). ${ }^{[4,5]}$

At the WC cutoff point, the WHO and European criteria consider both, IAF accumulation and subcutaneous fat accumulation, while the Japanese criteria emphasize on IAF accumulation. The WC cutoff points are reversed in males and females in Japan, because the amount of subcutaneous fat is greater in females than in males with the same IAF; however, there is substantial individual variation. ${ }^{[5]}$ While these criteria are well defined, the cut off points of some of the variables pertaining to the diagnostic items, such as WC, FPG level, and high-density lipoprotein-cholesterol (HDL-C) level are still controversial. ${ }^{[6]} \mathrm{A}$ Japanese study conducted between 2015 and 2017 reported that obesity was prevalent in $30.7 \%$ or $21.9 \%$ of males and females, respectively, and MetS was prevalent in $29.0 \%$ and $10.6 \%$ in the general adult population. Since the prevalence of MetS increases rapidly after the age of 40 years, it is presumed that there is a substantial proportion of individuals aged 20 to 30 years with pre-MetS, who are at high-risk of developing MetS. Although IAF accumulation is essential for the diagnosis of MetS in Japan, IAF has not been fully analyzed, particularly in young adults.

Abdominal computed tomography (CT) is the standard modality for evaluating IAF area (IAFA), but it has limitations due to radiation exposure problems, high cost, and the complexity of tracing the visceral fat region with the dedicated software. DUALSCAN is a non-invasive device, that can easily be used to measure the visceral fat through dual impedance analysis (dual bioelectrical impedance analysis [BIA]), and it has been reported to have good correlation with CT-measured IAFA. ${ }^{[7]}$

This study aimed to determine the prevalence of MetS among the Japanese population in their 20s and to verify whether IAF accumulation increases the risk of MetS in the future.

\section{Methods}

\subsection{Study design and participants}

This cross-sectional study was conducted between 2013 and 2018 and included 10691 participants in their 20s (6240 males and 4451 females). All the participants were students at Nagasaki University. They underwent annual health checkups including anthropometric measurements, laboratory analyses, and IAFA measurement, using the dual BIA instrument, DUALSCAN (Omron Dual scan HDS-2000; Omron, Kyoto, Japan). Informed consent was obtained from 9155 participants for undergoing IAFA measurement using the dual BIA instrument. Fasting blood samples were obtained from 2037 participants. Finally, we analyzed 1822 participants in their 20s (1163 males and 659 females), who provided informed consent and had complete data.

\subsection{Definition of metabolic syndrome}

In this study, we used the criteria proposed by the Japanese Committee for the Diagnostic Criteria of Metabolic Syndrome in $2005 .^{[4,5]}$ The clinical criteria for MetS requires the presence of IAF accumulation (WC of $\geq 85 \mathrm{~cm}$ and $\geq 90 \mathrm{~cm}$ in males and females, respectively, which corresponds to IAF accumulation of $\geq 100 \mathrm{~cm}^{2}$ ) and any 2 of the following three mild metabolic disorders:

(1) dyslipidemia (triglyceride $[\mathrm{TG}] \geq 150 \mathrm{mg} / \mathrm{dL}$ and/or HDL$\mathrm{C}<40 \mathrm{mg} / \mathrm{dL}$ ),
(2) increased BP (systolic blood pressure $[\mathrm{SBP}] \geq 130 \mathrm{mmHg}$ and/ or diastolic blood pressure $[\mathrm{DBP}] \geq 85 \mathrm{mmHg}$ ), and

(3) elevated blood glucose (FPG $\geq 110 \mathrm{mg} / \mathrm{dL})$.

\subsection{Anthropometric measurement and laboratory analyses}

Anthropometric factors including height, body weight, WC, and BP were measured. Each participant was asked to wear light clothing and no shoes during the measurements. Height and body weight were measured to the nearest $0.1 \mathrm{~cm}$ and $0.1 \mathrm{~kg}$, respectively, using an electronic scale with an attached stadiometer (TANITA DC-250). WC was measured at the midpoint between the lower costal margin and the level of the anterior superior iliac crest using a non-elastic tape (Mutoh W12A-88-15 J1S1). Abdominal obesity was defined as WC $\geq 85$ $\mathrm{cm}$ for males and $\geq 90 \mathrm{~cm}$ for females or an IAF of $\geq 100 \mathrm{~cm}^{2}$. BP was measured serially with an electrical sphygmomanometer (Japan Precision Instruments Inc. DM-3000). Participants were asked to rest quietly for over five minutes prior to the BPmeasurement. The representative values were calculated as follows: two measurements were taken with the participant in a sitting position, and the lower SBP measurement was chosen as the representative value. Blood was collected from the antecubital vein after overnight fasting. FPG, TG, and HDL-C were analyzed using standard laboratory methods.

\subsection{Dual BIA method and instrumentation}

The dual BIA instrument calculates the cross-sectional area of IAF at the level of the umbilicus based on the measurement of the electrical potentials resulting from the application of small electrical currents in the two body compartments. The principle of IAFA determination using the dual BIA instrument has been described previously. ${ }^{[8,9]}$ Other details of the study method have also been described previously. ${ }^{[8-12]}$

\subsection{Lifestyle assessment}

We assessed the participants' smoking status, drinking status, physical activity, and eating behavior using a self-reported questionnaire. Current smokers were defined as those smoking more than one cigarette per day, habitually. Current drinkers were defined as those drinking more than one alcohol drink per week, habitually. Physical activity was determined by asking the participants whether they belong to a sports clubs and/or if they walk more than 30 minutes per day. Eating behavior was evaluated based on the eating of breakfast almost every day.

\subsection{Statistical analysis}

All clinical data were summarized as means and standard deviations. An unpaired $t$ test or chi-square test was used for comparison between groups. To evaluate the relationship between IAFA and the three diagnostic MetS criteria, the participants were divided into four groups according to the IAFA (A1: 0-49.9; A2: 50-74.9; A3: 75-99.9; and A4: $100 \mathrm{~cm}^{2}$ ) and IAFA/WC [IAFA $\left(\mathrm{cm}^{2}\right) /$ WC (male, female) (cm): G1:-99/-84 or -89; G2:-99/85- or 90-; G3: 100-/-84 or -89; and G4: 100-/85- or 90-]. The crude odds ratios (ORs) and $95 \%$ confidence intervals (95\% CIs) of any 2 of the 3 MetS diagnostic criteria, as a dependent variable, were then compared with the smallest IAFA 


\section{Table 1}

Prevalence of metabolic syndrome and metabolic parameters according to the Japanese criteria.

\begin{tabular}{|c|c|c|c|c|c|}
\hline \multirow[b]{2}{*}{ Variables } & \multicolumn{2}{|c|}{ Male $(n=1163)$} & \multicolumn{2}{|c|}{ Female $(n=659)$} & \multirow[b]{2}{*}{$P$ value } \\
\hline & Mean \pm SD & n (\%) & Mean \pm SD & n (\%) & \\
\hline Age (yr) & $21.6 \pm 1.6$ & & $21.3 \pm 1.4$ & & $<.001$ \\
\hline BW $(\mathrm{kg})$ & $64.6 \pm 11.3$ & & $52.6 \pm 8.3$ & & $<.001$ \\
\hline Prevalence of MetS (\%) & & $38 / 1163$ (3.3) & & $0 / 659(0.0)$ & $<.001$ \\
\hline WC (cm) & $77.6 \pm 9.5$ & & $72.7 \pm 8.0$ & & $<.001$ \\
\hline IAFA $\left(\mathrm{cm}^{2}\right)$ & $47.0 \pm 25.3$ & & $33.1 \pm 15.0$ & & $<.001$ \\
\hline $\mathrm{TG}(\mathrm{mg} / \mathrm{dL})$ & $85.0 \pm 78.1$ & & $64.1 \pm 28.5$ & & $<.001$ \\
\hline $\mathrm{HDL}-\mathrm{C}(\mathrm{mg} / \mathrm{dL})$ & $57.9 \pm 10.8$ & & $67.6 \pm 11.5$ & & $<.001$ \\
\hline $\mathrm{FPG}(\mathrm{mg} / \mathrm{dL})$ & $85.5 \pm 7.8$ & & $84.8 \pm 6.4$ & & $<.05$ \\
\hline
\end{tabular}

Prevalence of MetS: MetS ratio shows the ratio of MetS in each age. It is not the ratio of each age to the total population.

$P$ value was calculated using the unpaired t test or chi-square test.

$\mathrm{BMI}=$ body mass index, $\mathrm{BW}=$ body weight, $\mathrm{DBP}=$ diastolic blood pressure, $\mathrm{FPG}=$ fasting plasma glucose, $\mathrm{HDL}-\mathrm{C}=$ high density lipoprotein-cholesterol, $\mathrm{IAFA}=\mathrm{Intra}-\mathrm{abdominal}$ fat area, $\mathrm{SBP}=$ systolic blood pressure, $\mathrm{TG}=$ triglycerides, $\mathrm{WC}=$ waist circumference.

(A1) and IAFA/WC-group (G1), as reference. Multivariate logistic regression was then conducted by sex, smoking status, drinking status, physical activity, and eating behavior using scores of the self-reported questionnaire as the adjusted variables. The significance threshold was $P<.05$. All analyses were performed using SPSS software, version 23.0 (SPSS Inc., IL).

\subsection{Ethical issues}

This study was approved by the research ethics committee of the Nagasaki University (approval number: 15013069), and informed consent was obtained from all participants.

\section{Results}

\subsection{Participant characteristics}

Table 1 shows the characteristics of the study population, with the prevalence of MetS and metabolic parameters. MetS was prevalent in $3.3 \%$ and $0.0 \%$ of the males and females, respectively, according to the Japanese MetS criteria. The IAFA was $47.0 \pm 25.3 \mathrm{~cm}^{2}$ and $33.1 \pm 15.0 \mathrm{~cm}^{2}$ for the males and females, respectively. Age, BW, BMI, MetS prevalence, WC, IAFA, SBP, DBP, TG, and FPG were significantly higher while HDL-C was significantly lower in males.

\subsection{Comparison between participants with and without abdominal obesity}

Comparison between participants with abdominal obesity defined according to WC $\geq 85 \mathrm{~cm}$ and IAFA $\geq 100 \mathrm{~cm}^{2}$ showed that MetS was prevalent in $18.7 \%$ or $0.0 \%$ of 203 males or 20 females with abdominal obesity (defined based on WC) and $41.0 \%$ or $0.0 \%$ of 39 males or 4 females (defined by IAFA), respectively (Tables 2 and 3). The values of BW, BMI, WC, IAFA, SBP, and DBP in males and those of BMI, WC, IAFA, and TG in females were higher in participants with abdominal obesity defined by IAFA than in those defined by WC (Tables 2 and 3).

We further compared the levels of MetS-related metabolic parameters between participants with and without abdominal obesity. There were significant differences in all parameters in those with abdominal obesity defined by IAFA except for age in males, and age and TG in females (Tables 2 and 3).

\subsection{Relationship between IAFA subgroups and MetS- related disorders}

To evaluate the relationship between the levels of IAFA and MetS-related metabolic disorders including dyslipidemia, high $\mathrm{BP}$, and high blood glucose, the participants were divided into 4 subgroups according to their IAFA designated groups, 1 through 4 (A1-4). Compared with group 1 (the smallest IAFA-group [A1]) values, the crude ORs and $95 \%$ CIs of MetS-related metabolic disorders were higher in all the groups with higher levels of IAFA (Table 4). After adjusting for sex, current smoking, current drinking, physical activity, and eating behavior, the significance of ORs were preserved (A2: OR: 4.80, 95\% confidence interval [CI]: 2.42-9.51;A3: OR: 7.34, 95\% CI: 3.01-17.89; A4: OR: 37.56, 95\% CI: 16.06-87.80).

\subsection{IAFA or WC as an index of visceral fat accumulation}

To evaluate the usefulness of the IAFA and WC as an index of abdominal obesity, the participants were divided into four groups according to 2 distinct definitions of abdominal obesity in the IAFA and WC designated groups, 1 through $4\left(\mathrm{G} 1\right.$ : IAFA $<100 \mathrm{~cm}^{2}$ and WC $<85 \mathrm{~cm}\left[\right.$ male] $/<90 \mathrm{~cm}$ [female]; G2: IAFA $<100 \mathrm{~cm}^{2}$ and WC $\geq 85 \mathrm{~cm}[\mathrm{male}] / \geq 90 \mathrm{~cm}$ [female]; G3: IAFA $\geq 100 \mathrm{~cm}^{2}$ and $\mathrm{WC}<$ $85 \mathrm{~cm}$ [male] $/<90 \mathrm{~cm}$ [female]; G4: IAFA $\geq 100 \mathrm{~cm}^{2}$ and WC $\geq 85$ $\mathrm{cm}[\mathrm{male}] / \geq 90 \mathrm{~cm}$ [female]). There were no participants in the G3 group in the current study. Compared with the G1 (no abdominal obesity by both, IAFA and WC) values, the crude ORs and 95\% CIs were elevated in G2 and G4, and were markedly increased in G4 (defined by both, IAFA and WC) rather than in G2 (WC alone) (G2: OR: 8.42 , 95\% CI: 4.76-15.21; G4: OR: 35.85 , 95\% CI: $17.28-$ 74.37). After adjusting for sex, current smoking, current drinking, physical activity, and eating behavior, the significance of ORs was preserved in G2 and G4 (G2: OR: 5.66, 95\% CI: 3.11-10.30; G4: OR: 24.56, 95\% CI: 11.56-52.19) (Table 5).

\subsection{Discussion and Conclusions}

The present study revealed that MetS was prevalent in 3.3\% and $0.0 \%$ of the males and females, respectively, in Japanese adults aged 20 to 30 years; the risk of MetS related disorders increased in young adult who had abdominal obesity. 
Table 2

Comparison between males with and without abdominal obesity.

\begin{tabular}{|c|c|c|c|c|c|c|c|c|c|}
\hline \multirow[b]{2}{*}{ Variables } & \multicolumn{4}{|c|}{ Abdominal obesity defined according to WC } & \multicolumn{4}{|c|}{ Abdominal obesity defined according to IAFA } & \multirow[b]{2}{*}{$P$ value } \\
\hline & & Mean \pm SD & n (\%) & $P$ value & & Mean \pm SD & n (\%) & $P$ value & \\
\hline $\mathrm{N}$ & $\begin{array}{l}W C<85 \mathrm{~cm} \\
W C \geq 85 \mathrm{~cm}\end{array}$ & & $\begin{array}{l}960 \\
203\end{array}$ & & $\begin{array}{l}\text { IAFA }<100 \mathrm{~cm}^{2} \\
\text { IAFA } \geqq 100 \mathrm{~cm}^{2}\end{array}$ & & $\begin{array}{c}1124 \\
39\end{array}$ & & \\
\hline BW (kg) & $\begin{array}{l}W C<85 \mathrm{~cm} \\
W C \geq 85 \mathrm{~cm}\end{array}$ & $\begin{array}{c}61.0 \pm 6.9 \\
82.8 \pm 11.6\end{array}$ & & $<.001$ & $\begin{array}{l}\text { IAFA }<100 \mathrm{~cm}^{2} \\
\text { IAFA } \geqq 100 \mathrm{~cm}^{2}\end{array}$ & $\begin{array}{c}63.5 \pm 9.4 \\
99.3 \pm 10.0\end{array}$ & & $<.001$ & $\begin{array}{l}<.001 \\
<.001\end{array}$ \\
\hline BMI $\left(\mathrm{kg} / \mathrm{m}^{2}\right)$ & $\begin{array}{l}W C<85 \mathrm{~cm} \\
W C \geq 85 \mathrm{~cm}\end{array}$ & $\begin{array}{l}20.8 \pm 2.0 \\
27.5 \pm 3.5\end{array}$ & & $<.001$ & $\begin{array}{l}\text { IAFA }<100 \mathrm{~cm}^{2} \\
\text { IAFA } \geqq 100 \mathrm{~cm}^{2}\end{array}$ & $\begin{array}{l}21.5 \pm 2.8 \\
32.9 \pm 2.9\end{array}$ & & $<.001$ & $\begin{array}{l}<.001 \\
<.001\end{array}$ \\
\hline WC (cm) & $\begin{array}{l}W C<85 \mathrm{~cm} \\
W C \geq 85 \mathrm{~cm}\end{array}$ & $\begin{array}{l}74.2 \pm 5.3 \\
93.7 \pm 8.4\end{array}$ & & $<.001$ & $\begin{array}{l}\text { IAFA }<100 \mathrm{~cm}^{2} \\
\text { IAFA } \geqq 100 \mathrm{~cm}^{2}\end{array}$ & $\begin{array}{c}76.5 \pm 7.9 \\
106.3 \pm 6.8\end{array}$ & & $<.001$ & $\begin{array}{l}<.001 \\
<.001\end{array}$ \\
\hline IAFA $\left(\mathrm{cm}^{2}\right)$ & $\begin{array}{l}W C<85 \mathrm{~cm} \\
W C \geq 85 \mathrm{~cm}\end{array}$ & $\begin{array}{l}39.7 \pm 16.8 \\
80.0 \pm 31.6\end{array}$ & & $<.001$ & $\begin{array}{l}\text { IAFA }<100 \mathrm{~cm}^{2} \\
\text { IAFA } \geqq 100 \mathrm{~cm}^{2}\end{array}$ & $\begin{array}{c}43.6 \pm 19.3 \\
132.8 \pm 26.3\end{array}$ & & $<.001$ & $\begin{array}{l}<.001 \\
<.001\end{array}$ \\
\hline $\mathrm{SBP}(\mathrm{mmHg})$ & $\begin{array}{l}W C<85 \mathrm{~cm} \\
W C \geq 85 \mathrm{~cm}\end{array}$ & $\begin{array}{l}122.6 \pm 9.5 \\
131.1 \pm 9.4\end{array}$ & & $<.001$ & $\begin{array}{l}\text { IAFA }<100 \mathrm{~cm}^{2} \\
\text { IAFA } \geqq 100 \mathrm{~cm}^{2}\end{array}$ & $\begin{array}{l}123.7 \pm 9.9 \\
134.6 \pm 8.6\end{array}$ & & $<.001$ & $\begin{array}{l}<.05 \\
<.05\end{array}$ \\
\hline $\mathrm{HDL}-\mathrm{C}(\mathrm{mg} / \mathrm{dL})$ & $\begin{array}{l}W C<85 \mathrm{~cm} \\
W C \geq 85 \mathrm{~cm}\end{array}$ & $\begin{array}{l}59.1 \pm 10.5 \\
52.4 \pm 10.2\end{array}$ & & $<.001$ & $\begin{array}{l}\text { IAFA }<100 \mathrm{~cm}^{2} \\
\text { IAFA } \geqq 100 \mathrm{~cm}^{2}\end{array}$ & $\begin{array}{c}58.2 \pm 10.7 \\
49.5 \pm 8.7\end{array}$ & & $<.001$ & $\begin{array}{l}.07 \\
.09\end{array}$ \\
\hline $\mathrm{FPG}(\mathrm{mg} / \mathrm{dL})$ & $\begin{array}{l}W C<85 \mathrm{~cm} \\
W C \geq 85 \mathrm{~cm}\end{array}$ & $\begin{array}{l}85.1 \pm 7.3 \\
87.2 \pm 7.9\end{array}$ & & $<.001$ & $\begin{array}{l}\text { IAFA }<100 \mathrm{~cm}^{2} \\
\text { IAFA } \geqq 100 \mathrm{~cm}^{2}\end{array}$ & $\begin{array}{l}85.3 \pm 7.4 \\
89.8 \pm 8.2\end{array}$ & & $<.001$ & $\begin{array}{l}.51 \\
.07\end{array}$ \\
\hline
\end{tabular}

Prevalence of MetS: MetS ratio shows the ratio of MetS in each category. It is not the ratio of each category to the total population.

$P$ value was calculated using the unpaired t test or chi-square test.

* $P$ value for non-abdominal obesity vs abdominal obesity $\left(W C<85 \mathrm{~cm}\right.$ vs WC $\geq 85 \mathrm{~cm} /$ IAFA $<100 \mathrm{~cm}^{2}$ vs IAFA $\geq 100 \mathrm{~cm}^{2}$ ).

${ }^{\dagger} P$ value for WC vs IAFA.

$\mathrm{BMI}=$ body mass index, $\mathrm{BW}=$ body weight, $\mathrm{DBP}=$ diastolic blood pressure, $\mathrm{IAFA}=$ intra-abdominal fat area, $\mathrm{SBP}=$ systolic blood pressure, $\mathrm{TG}=$ triglycerides, $\mathrm{WC}=$ waist circumference

Table 3

Comparison between females with and without abdominal obesity.

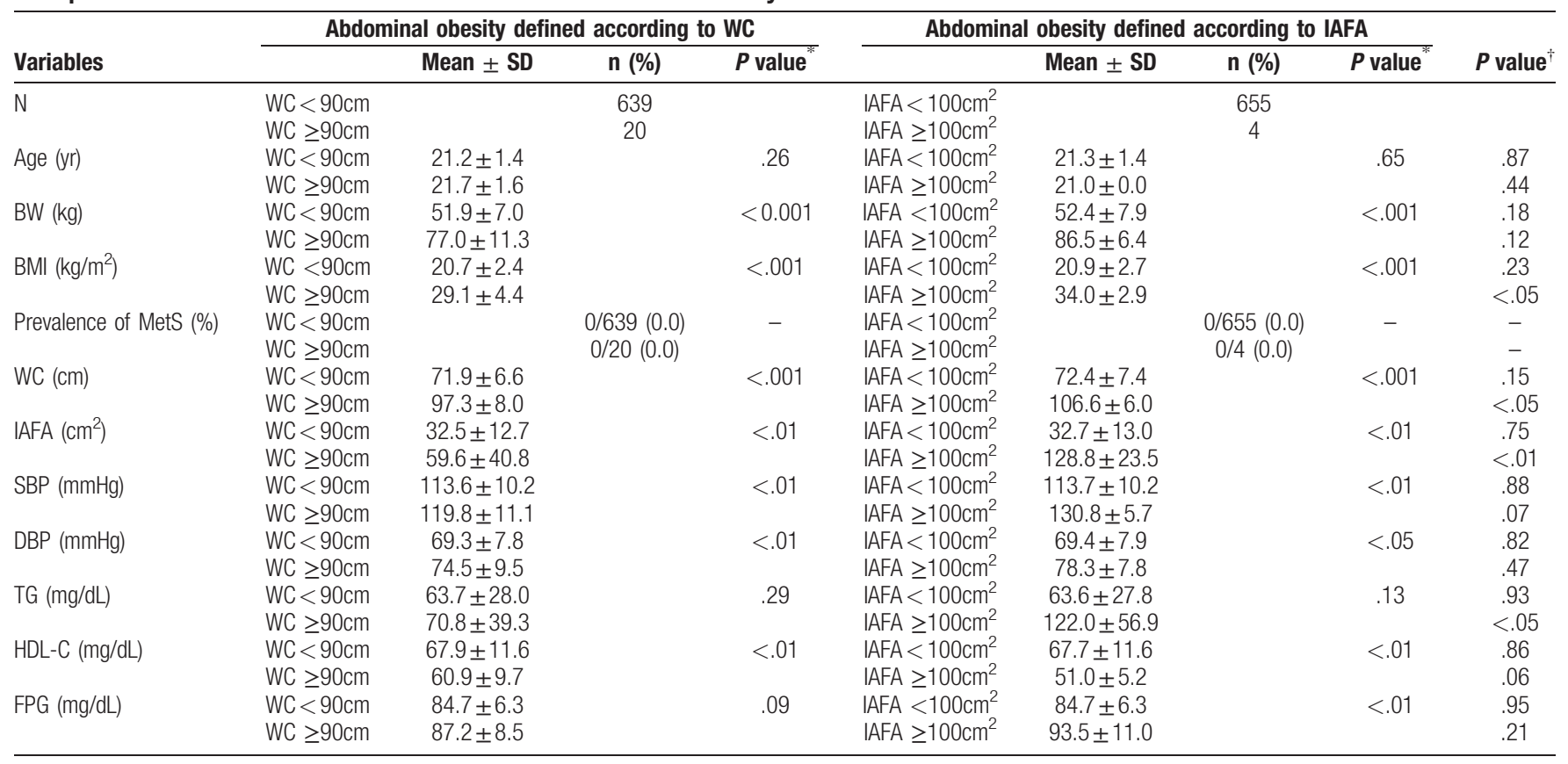

Prevalence of MetS: MetS ratio shows the ratio of MetS in each category. It is not the ratio of each category to the total population.

$P$ value was calculated using the unpaired $t$ test or chi-square test.

${ }^{*} P$ value for non-abdominal obesity vs abdominal obesity (WC $<85 \mathrm{~cm}$ vs $W C \geq 85 \mathrm{~cm} /$ IAFA $<100 \mathrm{~cm}^{2}$ vs IAFA $\left.\geq 100 \mathrm{~cm}^{2}\right)$.

$\uparrow P$ value for WC vS IAFA.

$\mathrm{BMI}=$ body mass index, $\mathrm{BW}=$ body weight, $\mathrm{DBP}=$ diastolic blood pressure, $\mathrm{IAFA}=$ intra-abdominal fat area, $\mathrm{SBP}=$ systolic blood pressure, $\mathrm{TG}=$ triglycerides, $\mathrm{WC}=$ waist circumference 
Table 4

Relationship between intra-abdominal fat area and the risk of any two of the three diagnostic criteria for metabolic syndrome.

\begin{tabular}{lccc}
\hline Variables & $\begin{array}{c}\text { Number of persons with any two } \\
\text { criteria / number of participants (\%) }\end{array}$ & $\begin{array}{c}\text { Crude odds } \\
\text { ratio (95\% Cl) }\end{array}$ & $\begin{array}{r}\text { Adjusted for sex, smoking, drinking, } \\
\text { exercise, and eating behavior (95\% Cl) }\end{array}$ \\
\hline IAFA $\left(\mathrm{cm}^{2}\right)$ & $13 / 1305(1.0)$ & 1.00 (reference value) & 1.00 (reference value) \\
A1: $0-49$ & $26 / 393(6.6)$ & $7.04(3.58-13.84)$ & $4.80(2.42-9.51)$ \\
A2: $50-74$ & $9 / 81(11.1)$ & $12.42(5.14-30.02)$ & $7.34(3.01-17.89)$ \\
A3: $75-99$ & $16 / 43(37.2)$ & $58.90(25.81-134.41)$ & $37.56(16.06-87.80)$ \\
A4: $100 \geq$ & & \\
\hline
\end{tabular}

A1-4: Four groups of participants according to the IAFA level.

$\mathrm{Cl}=$ confidence interval, IAFA = intra-abdominal fat area.

Our results have shown that a certain population of young adult males, but not females has MetS in Japan. Few studies had investigated the risk of MetS in young adults. In these previous reports, the prevalence of MetS ranged from $3.7 \%$ to $10 \% .^{[3,13]}$ Another study reported an increasing IAF distribution in boys, but not girls in Japanese non-obese children aged older than 10 years. ${ }^{[14]}$ We have previously reported the relationship between IAF accumulation and hypertension in males, but not in females in our university students. ${ }^{[12]}$ Although there could be a sex difference in IAFA in Japanese young adults, our study revealed that almost all levels of MetS components were significantly elevated in both, males and females with abdominal obesity. These findings indicate that a substantial proportion of those aged 20 to 30 years with pre-MetS have a risk of developing MetS in the future, irrespective of sex.

In the clinical setting in Japan, IAF accumulation is often evaluated by measuring WC at the umbilical level. ${ }^{[14]}$ Several previous studies in Japan demonstrated a strong correlation between the level of umbilical WC and the risk of MetS ${ }^{[15,16]}$; however, this method is not used internationally. ${ }^{[17-20]}$ The Japan Obesity Society proposed a standard WC $\geq 85 \mathrm{~cm}$ for males and $\geq 90 \mathrm{~cm}$ for females as the main diagnostic criteria of MetS, corresponding to an IAF accumulation of $\geq 100 \mathrm{~cm}^{2}$ based on a study in adults aged approximately 55 years. ${ }^{[21]}$ In Japan, metabolic health check-up diagnosis is heavily based on the WC. However, recently, even if the WC is within the standard limit, the existence of "hidden metabolism" with dyslipidemia, high BP, and high blood sugar level has been regarded as a problem. Approximately more than 9 million Japanese aged over 40 years have "hidden metabolism". ${ }^{[22]}$ The current method of taking WC measurements first overlook the "hidden metabolism" and cannot identify the risks for other diseases such as cardiovascular disease or stroke. Thus, urgent measures against "hidden metabolism" are needed in adults. In this context, it is questionable whether the WC levels in adults can be used to diagnose MetS in young adults in their 20s or to predict MetSrelated metabolic disorders, which can consequently lead to the development of MetS in the future. To evaluate the usefulness of the definition of MetS by WC, corresponding to IAF accumulation in young adults, we compared several MetS-related metabolic parameters between participants with and without abdominal obesity, defined by WC and IAFA using a noninvasive device, DUALSCAN.

The mean level of IAF in the group with abdominal obesity defined by WC was only $80.0 \pm 31.6 \mathrm{~cm}^{2}$, and was significantly smaller than that by IAFA $\left(132.8 \pm 26.3 \mathrm{~cm}^{2} P<.01\right)$, indicating that the definition of abdominal obesity by WC was overestimated. The definition by IAFA $\geq 100 \mathrm{~cm}^{2}$ was more predictable for the diagnosis of MetS among participants with abdominal obesity compared to that by WC $(18.7 \%$ (38/203) vs $41.0(16 / 39), P<.05)$, since the number of those with abdominal obesity estimated by WC was significantly larger than that by IAFA. Further, almost all the values of MetS components were significantly elevated based on the levels of IAFA. Interestingly, in our study, the risk markedly increased in participants with abdominal obesity defined by both, IAFA and WC rather than by WC alone. Taken together with these results, the IAFA could be a better index of the definition of abdominal obesity rather than WC as one of the criteria of MetS in young adults in their 20s.

The present study has several strengths, including the direct assessment of IAF using DUALSCAN; this allowed for precise analysis of the relationship between IAF and MetS in adults in their 20s. In addition, we had a reasonable sample size ( $>1000$ subjects). Nevertheless, this study also had a limitation. The study subjects were chosen from one place (Nagasaki university), which was not representative of the general population. However, we confirm a similar mean BMI between our participants and the participants in the National Nutrition Survey in Japan (annual

\section{Table 5}

Relationship between intra-abdominal fat area /waist circumference and risk of any 2 of the 3 MetS diagnostic criteria.

\begin{tabular}{|c|c|c|c|c|c|}
\hline & Variables & $\begin{array}{l}\text { Number of persons with any two } \\
\text { criteria / number of participants (\%) }\end{array}$ & $\begin{array}{l}\text { Crude odds } \\
\text { ratio }(95 \% \mathrm{CI})\end{array}$ & $\begin{array}{l}\text { Adjusted for sex, smoking, drinking, } \\
\text { exercise, and eating behavior ( } 95 \% \mathrm{CI})\end{array}$ & \\
\hline & IAFA $\left(\mathrm{cm}^{2}\right)$ & WC (male/female) (cm) & & & \\
\hline G1 & $<100$ & $<85 /<90$ & 26 / 1599 (1.6) & 1.00 (reference value) & 1.00 (reference value) \\
\hline G3 & $100 \geq$ & $<8 \overline{5} /<\overline{90}$ & $0 / 0(0)$ & - & - \\
\hline G4 & $100 \geq$ & $85 \geq / 90 \geq$ & 16 / $43(37.2)$ & 35.85 (17.28-74.37) & $24.56(11.56-52.19)$ \\
\hline
\end{tabular}

G1-4: Four groups of participants according to IAFA and WC levels.

$\mathrm{Cl}=$ confidence interval, IAFA = intra-abdominal fat area, $\mathrm{WC}=$ waist circumference. 
report of the National Health and Nutrition Survey in 20132017). ${ }^{[23]}$ This indicates that our results could be representative of the general population.

In conclusion, the MetS among the Japanese population in their 20s was less prevalent than those in adults. However, IAF accumulation was significantly associated with MetS-related metabolic disorders in young adulthood. Thus, IAF measurements in young adults may be useful for the identification of those at high-risk of developing MetS in later life.

\section{Acknowledgments}

The authors thank Ms. Mayumi Maeda, Ms. Yoko Seike, Ms. Yuko Kuroki, and Ms. Kana Yoshida of the Center for Health and Community Medicine, Nagasaki University, Nagasaki, Japan for their technical assistance. We would like to thank Editage (www.editage.com) for English language editing.

\section{Author contributions}

MK and SO designed and coordinated the study; JT, IS, TK, MH, and SS provided the information about the physiological variables; SO and JT analyzed the data; PB and NA interpreted the data. All authors have read and approved the final manuscript.

\section{References}

[1] Grundy SM, Brewer HB, Cleeman JI, et al. Definition of metabolic syndrome. Circulation 2004;109:433-8.

[2] Eckel RH, Grundy SM, Zimmet PZ. The metabolic syndrome. Lancet 2005;365:1415-28.

[3] Fernandes J, Lofgren IE. Prevalence of metabolic syndrome and individual criteria in college students. J Am Coll Health 2011;59:313-21.

[4] Matsuzawa Y. Metabolic syndrome-definition and diagnostic criteria in Japan. J Jpn Soc Int Med 2005;94:188-203. (in Japanese).

[5] Matsuzawa Y. Metabolic syndrome-definition and diagnostic criteria in Japan. J Atheroscler Thromb 2005;12:301.

[6] Sugawara A, Sone H. Evidence for the diagnosis of metabolic syndrome in Japan. Jpn J Nutr Diet 2011;69:205-13.

[7] Yamakage H, Ito R, Tochiya M, et al. The utility of dual bioelectrical impedance analysis in detecting intra-abdominal fat area in obese patients during weight reduction therapy in comparison with waist circumference and abdominal CT. Endocr J 2014;61:807-19.

[8] Yoneda M, Tasaki H, Tsuchiya N, et al. A study of bioelectrical impedance analysis methods for practical visceral fat estimation. In: IEEE., International Conference on Granular Computing, (GCR., 2007), Lin, T.Y., et, al., eds., IEEE Computer Society Press. 2007:622-27.
[9] Shiga T, Hamaguchi T, Oshima Y, Kanai H, Hirata M. A new simple measurement system of visceral fat accumulation by bioelectrical impedance analysis. In IFMBE Proceedings Vol. 25/7: World Congress on Medical Physics and Biomedical Engineering, Döossel O, et al., eds., Springer-Verlag; 2009:338-41.

[10] Shiga T, Oshima Y, Kanai H, Hirata M, Hosoda K, Nakao K. A simple measurement method of visceral fat accumulation by bioelectrical impedance analysis, In: IFMBE., Proceedings, Vol., 17/14: 13th International Conference on Electrical Bioimpedance, the 8th Conference on Electrical Impedance Tomography, Scharfetter, H., et, al., eds., Springer-Verlag; 2007:687-90.

[11] Ida M, Hirata M, Odori S, et al. Early changes of abdominal adiposity detected with weekly dual bioelectrical impedance analysis during calorie restriction. Obesity (Silver Spring) 2013;21:E350-3.

[12] Takeoka A, Tayama J, Yamasaki H, et al. Intra-abdominal fat accumulation is a hypertension risk factor in young adulthood: a cross-sectional study. Medicine (Baltimore) 2016;95:e5361.

[13] Keown TL, Smith CB, Harris MS. Metabolic syndrome among college students. J Nurse Pract 2009;5:754-9.

[14] Satake E, Nakagawa Y, Kubota A, et al. Age and sex differences in fat distribution in non-obese Japanese children. J Pediatr Endocrinol Metab 2010;23:873-8.

[15] Eguchi Y, Eguchi T, Mizuta T, et al. Visceral fat accumulation and insulin resistance are important factors in nonalcoholic fatty liver disease. J Gastroenterol 2006;41:462-9.

[16] Ninomiya T, Kubo M, Doi Y, et al. Impact of metabolic syndrome on the development of cardiovascular disease in a general Japanese population: the Hisayama study. Stroke 2007;38:2063-9.

[17] Matsushita Y, Tomita K, Yokoyama T, et al. Relations between waist circumference at four sites and metabolic risk factors. Obesity (Silver Spring) 2010;18:2374-2378.

[18] Okazawa T, Iwata M, Matsushita Y, et al. Aging attenuates the association of central obesity with the accumulation of metabolic risk factors when assessed using the waist circumference measured at the umbilical level (the Japanese standard method). Nutr Diabetes 2013;3:e96.

[19] Yokoyama H, Hirose H, Kanda T, et al. Relationship between waist circumferences measured at the umbilical level and midway between the ribs and iliac crest - a solution to the debate on optimal waist circumference standards in the diagnostic criteria of metabolic syndrome in Japan. J Atheroscler Thromb 2011;18:735-43.

[20] Matsushita R, Isojima T, Takaya R, et al. Development of waist circumference percentiles for Japanese children and an examination of their screening utility for childhood metabolic syndrome: a populationbased cross-sectional study. BMC Public Health 2015;15:1121.

[21] The Examination Committee of Criteria for 'Obesity Disease' in Japan, Japan Society for the Study of ObesityNew Criteria for 'Obesity Disease' in Japan. Circ J 2002;66:987-92.

[22] Shimokata H. Estimation of the number of patients with metabolically obese normal weight: from a community-living cohort study. Nagoya J Nutr Sci 2018;37-43.

[23] Ministry of Health, Labour and Welfare home page [Internet]. National Health and Nutrition Survey. Available from: https://www.mhlw.go.jp/ bunya/kenkou_eiyou_chousa.html (in Japanese). 